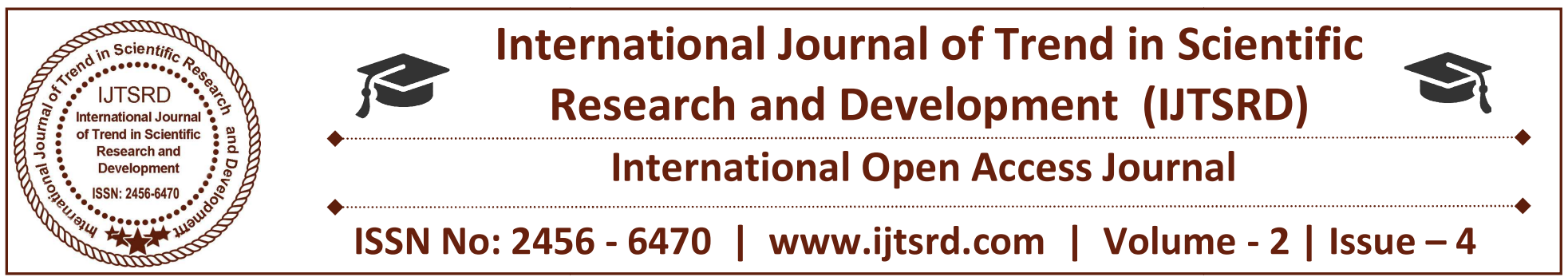

\title{
Optimizing Strength of A Retaining Wall By Altering Reinforcement Details
}

\author{
Snehal V. Dewalkar ${ }^{1}$, Mr. Sumit Sanghani ${ }^{2}$, Mr. Siddharth Saswade ${ }^{2}$, \\ Mr. Piyush Savtekar ${ }^{2}$, Mr. Shubham Sawant ${ }^{2}$, Mr. Krishna Soni ${ }^{2}$ \\ ${ }^{1}$ Assistant Professor, ${ }^{2}$ Student, \\ Civil Engineering Department, Sinhgad Academy of Engineering, \\ Kondhwa, Pune, Maharashtra, India
}

\section{ABSTRACT}

Retaining walls are structures designed to restrain soil to a slope that it would not naturally keep to (typically a steep, near-vertical or vertical slope). The most important consideration in proper design and installation of retaining walls is to recognize and counteract the tendency of the retained material to move downslope due to gravity. This creates lateral earth pressure behind the wall which depends on the angle of internal friction (phi) and the cohesive strength (c) of the retained material, as well as the direction and magnitude of movement the retaining structure undergoes. Lateral earth pressures are zero at the top of the wall and - in homogenous ground 2 increase proportionally to a maximum value at the lowest depth. Earth pressures will push the wall forward or overturn it if not properly addressed. Also, any groundwater behind the wall that is not dissipated by a drainage system causes hydrostatic pressure on the wall. The total pressure or thrust may be assumed to act at one-third from the lowest depth for lengthwise stretches of uniform height. Unless the wall is designed to retain water, It is important to have proper drainage behind the wall in order to limit the pressure to the wall's design value. Drainage materials will reduce or eliminate the hydrostatic pressure and improve the stability of the material behind the wall. Drystone retaining walls are normally self-draining. As an example, the International Building Code requires retaining walls to be designed to ensure stability against overturning, sliding, excessive foundation pressure and water uplift; and that they be designed for a safety factor of 1.5 against lateral sliding and overturning.

The main aim of this study is to see behaviour and analysis of retaining wall with the different reinforcement detailing using software. Performing different practical model test. Comparison of strength and cost of retaining wall with and without altering reinforcement details.

Keywords: Cantilever retaining wall, Internal friction, Lateral pressure ,Reinforcement details.

\section{INTRODUCTION}

A retaining wall is a structure designed and constructed to resist the lateral pressure of soil, when there is a desired change in ground elevation that exceeds the angle of repose of the soil. A basement wall is thus one kind of retaining wall. But the term usually refers to a cantilever retaining wall, which is a freestanding structure without lateral support at its top. These are cantilevered from a footing and rise above the grade on one side to retain a higher level grade on the opposite side. The walls must resist the lateral pressures generated by loose soils or, in some cases, water pressures. Every retaining wall supports a "wedge" of soil. The wedge is defined as the soil which extends beyond the failure plane of the soil type present at the wall site, and can be calculated once the soil friction angle is known. As the setback of the wall increases, the size of the sliding wedge is 
reduced. This reduction lowers the pressure on the retaining wall.

The most important consideration in proper design and installation of retaining walls is to recognize and counteract the tendency of the retained material to move down slope due to gravity. This creates lateral earth pressure behind the wall which depends on the angle of internal friction (phi) and the cohesive strength (c) of the retained material, as well as the direction and magnitude of movement the retaining structure undergoes. Lateral earth pressures are zero at the top of the wall and - in homogenous ground increase proportionally to a maximum value at the lowest depth. Earth pressures will push the wall forward or overturn it if not properly addressed. Also, any groundwater behind the wall that is not dissipated by a drainage system causes hydrostatic pressure on the wall. The total pressure or thrust may be assumed to act at one-third from the lowest depth for lengthwise stretches of uniform height. Unless the wall is designed to retain water, It is important to have proper drainage behind the wall in order to limit the pressure to the wall's design value. Drainage materials will reduce or eliminate the hydrostatic pressure and improve the stability of the material behind the wall. Drystone retaining walls are normally selfdraining. As an example, the International Building Code requires retaining walls to be designed to ensure stability against overturning, sliding, excessive foundation pressure and water uplift; and that they be designed for a safety factor of 1.5 against lateral sliding and overturning.

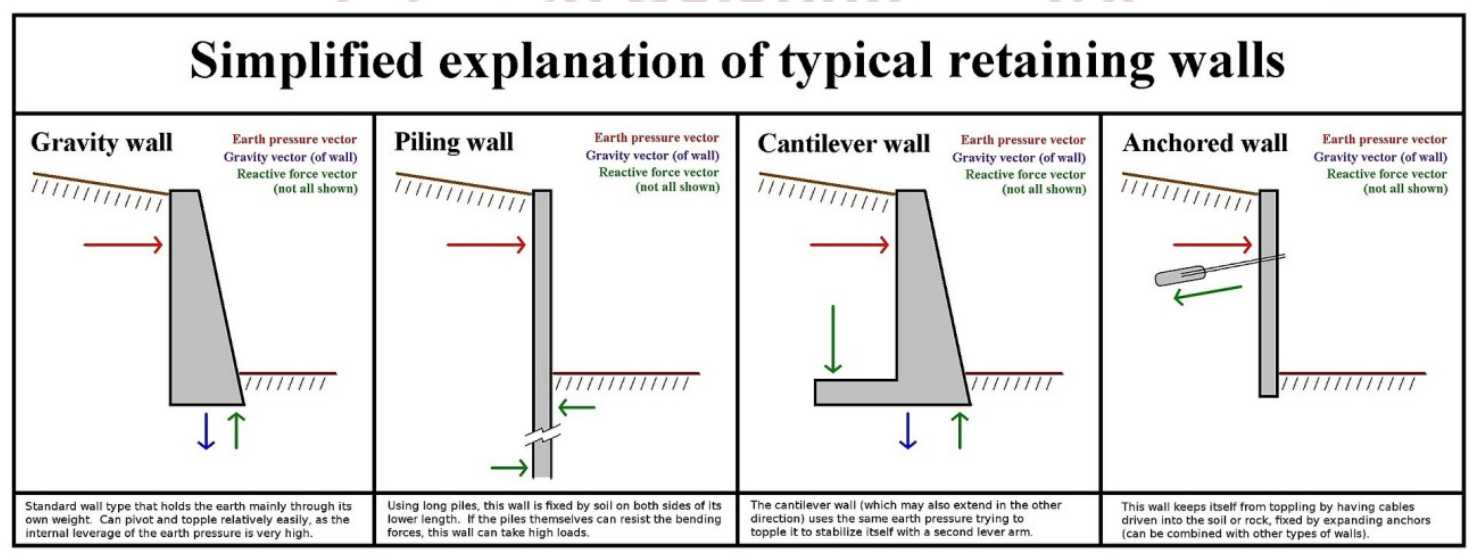

Figure 1.Simplified explanation of typical retaining wall
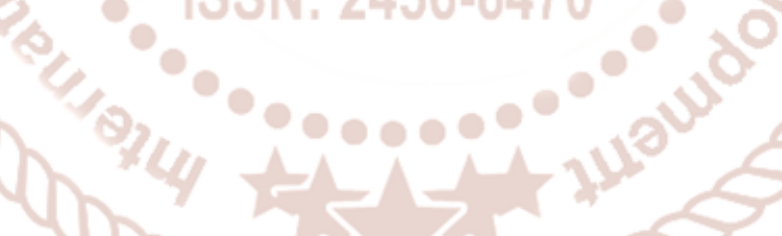

figure 2. Common Terminology 


\section{TYPES OF RETAINING WALL FAILURE}
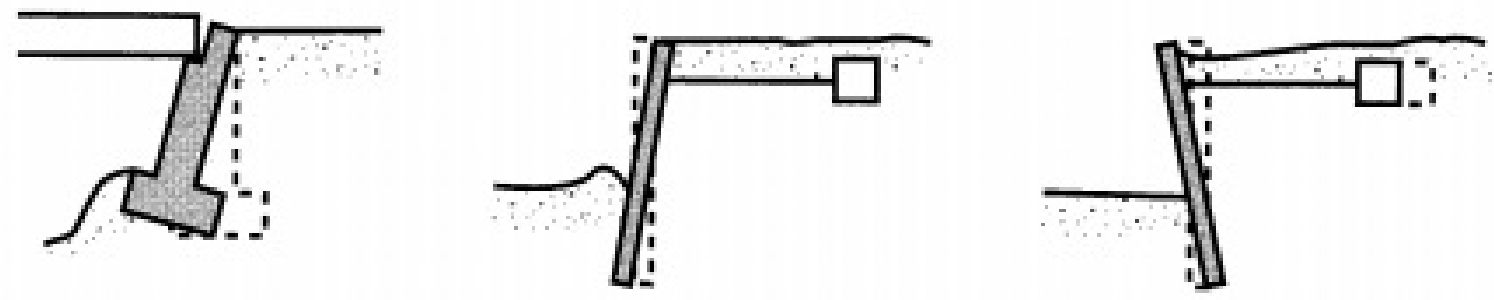

Figure 3 .Types of failure (sliding, overturning and bending respectively.)

\section{LITERATURE REVIEW}

$>$ Robert W. Day concluded that most retaining wall failures are gradual, cantilever retaining walls fails slowly by the intermittently tilting or moving laterally.

$>$ In the work done by A. Rouili the results of a numerical analysis are presented, different wall geometries were considered. The results show that the proportioning governs the equilibrium between the instantaneous rotation and the translation of the wall-toe; also, the length of the wall base through the ratio $\mathrm{B} / \mathrm{H}$ governs the equilibrium between the instantaneous rotation and the translation of the wall-toe.

$>$ John. S. Havarth studied the behaviour of cantilever retaining wall with respect to footing shape. He used finite element method. The computer software SSTIPNH was used.

$>$ G.L. Sivakumarbabu and B. Munwarbasha published a paper 'optimum design of cantilever retaining walls using target reliability approach in journal available as ascelibrary.org which is copyrighted to American society of civil engineers.

$>$ The author A. Kaveh, A. Shakouri Mahmud abadi discussed harmonic algorithms method. It considers cost of the structure as an objective function and it's subjected to a structural design constants.

\section{PROBLEM STATEMENT}

For the construction in the area having very high ground slopes and also for maintain the stability of hilly regions use of retaining wall is increasing which shares a very large amount of construction cost.

Therefore it is very essential to reduce the cost of retaining wall construction reducing failure risk.

\section{AIM AND OBJECTIVE}

1) Analysis of retaining wall with the different reinforcement detailing using software.

2) Performing different practical model test.

3) Comparison of strength and cost of retaining wall with and without altering reinforcement details.

\section{CONCLUSION}

Increase in strength and reduction in cost of retaining wall are to be concluded.

The project consists of increasing strength of retaining wall and reducing the cost using different reinforcement detailing patterns.

Expected result is it will increase the strength approximately $150 \%$ than normal practices ,Staggered bars gives more strength than parallel bar reinforcement.

\section{REFERENCES}

1) Robert W. Day, Fellow, ASCE.Design and construction of cantilevered retaining walls, American Society of Civil Engineers,Practice Periodical on Structural Design and ConstructionVol. 2, Issue 1 (February 01, 1997).

2) Ahmed Rouili. On the design of L-shaped retaining walls, World Academy of Science, Engineering and Technology, International Journal of Civil Science and Engineering Vol: 7 No:12, 2013.

3) John S. Horvath, Member, ASCE. Effect of Footing Shape on Behavior of Cantilever Retaining Wall, Journal of Geotechnical EngineeringVol. 117, Issue 6 (June 01, 1991).

4) Ortiz, R. F. Scott, J. Lee. Dynamic centrifuge testing of a cantilever retaining wall, Earthquake Engineering \& Structural Dynamics, Volume 11, Issue 2 March/April 1983 Pages 251-268. 
5) A. B. Fourie, D. M. Potts. Comparison of finite element and limiting equilibrium analyses for an embedded cantilever retaining wall, Geotechnique Vol 39, No. 2, 175-188, June 1989.

6) G. L. SivakumarBabu and B. MunwarBasha. Optimum design of cantilever retaining walls using target reliability approach, American Society of Civil Engineers, International Journal of Geomechanics Vol. 8, Issue 4 (July 01, 2008)
7) A. kaveh, A. shakouri Mahmud abadi. Harmony search based algorithms for the optimum cost design of reinforced concrete cantilever retaining walls, International Journal of Civil Engineering, Vol 9, No. 1, March 2011

8) 2006 International Building Code Section 1806.

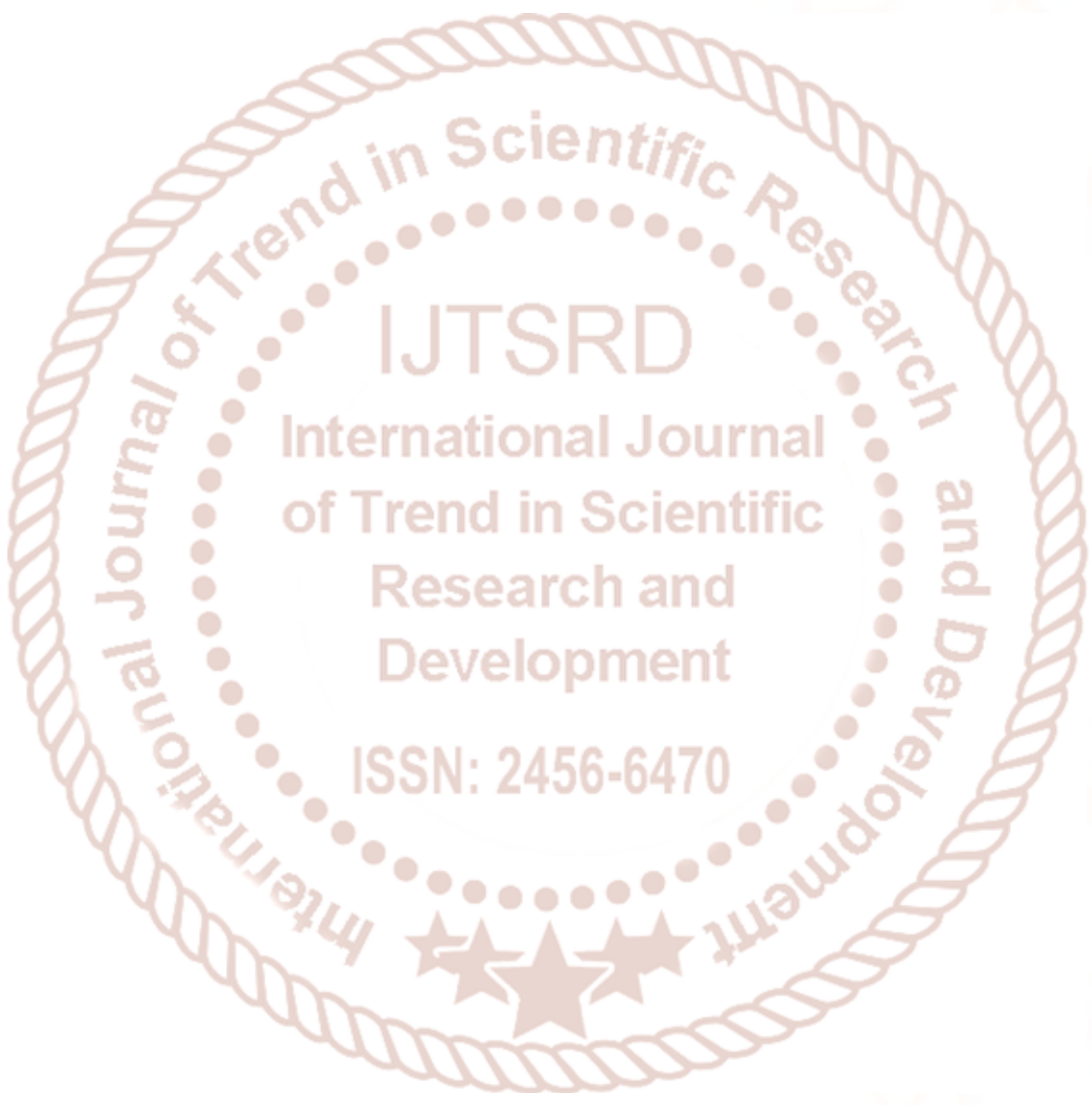

